\title{
Intravenous Thrombolysis and Risk Factors for Ischemic Stroke
}

\author{
Shakti Shrestha, ${ }^{1}$ Ramesh Sharma Poudel, ${ }^{2}$ Lekhiung Thapa, ${ }^{3}$ Dipendra Khatiwada ${ }^{4}$ \\ 'Department of Pharmacy, Shree Medical and Technical College, Chitwan, Nepal, ${ }^{2}$ Hospital Pharmacy, Chitwan Medical \\ College Teaching Hospital, Chitwan Nepal, ${ }^{3}$ National Institute of Neurological and Allied Sciences, Kathmandu, Nepal, \\ ${ }^{4}$ Department of Community Medicine, College of Medical Sciences-Teaching Hospital, Chitwan, Nepal.
}

\section{ABSTRACT}

Thrombolysis is one of the proven potential treatments for the management of acute ischemic stroke. Intravenous recombinant tissue-plasminogen activator (rt-PA) is the only medically approved biological thrombolysing agent for the treatment of acute ischemic stroke within $4.5 \mathrm{~h}$ of stroke $(2.2 \%$ symptomatic intracerebral haemorrhage, $12.7 \%$ mortality and $58.0 \%$ functional independence), but following the guideline and criteria provided by National Institute of Neurological Disorder and Stroke (NINDS) and SITS (Safe Implementation of Thrombolysis in Stroke) studies. Nepal needs to evidently introduce intravenous rt-PA in its clinical setting for treatment of acute ischemic stroke, which has been approved for more than a decade ago in developed countries. Several modifiable and non-modifiable risk factors can affect the outcomes of the treatment with intravenous rt-PA. Early modification of factors predicting the risk outcomes can be a beneficial tool to justify the thrombolytic treatment. This review aims to discuss the major studies on thrombolysis using rt-PA and main factors that can affect the outcomes of treatment in ischemic stroke.

Keywords: alteplase; ischemic stroke; risk factors; rt-PA; thrombolysis.

\section{INTRODUCTION}

Stroke is one of the global causes of mortality and morbidity with nearly 16 million annual first ever stroke, causing a total of 5.7 million deaths worldwide. ${ }^{1}$ The total cost for stroke care in the United States in 2008 was estimated at $\$ 65.5$ billion, ${ }^{2}$ in 27 European Union countries at $€ 27$ billion $^{3}$ and the United Kingdom at $£ 8.9$ billion per annum. ${ }^{4}$ Due to rapid population aging and lifestyle modifications stroke is increasingly hitting Asian countries including Nepal. ${ }^{5}$ Earlier treatment of ischemic stroke can lead to favourable outcomes ${ }^{6}$ and thus, can reduce the burden to a larger extent.
Early modification of the useful predictors of outcomes after acute and sub-acute stroke such as age, neurological condition, blood pressure, glucose concentration, body temperature, duration of symptoms, scan findings, previous stroke can be a beneficial tool for the treatment of stroke. ${ }^{6-8}$ This review aims to discuss the major studies on thrombolysis using rt-PA and chief factors that can affect the outcomes of treatment in ischemic stroke.

Correspondence: Shakti Shrestha, Department of Pharmacy, Shree Medical and Technical College, Bharatpur-12, Chitwan, Nepal. Email: shaktishrestha@yahoo.com, Phone: +977-9855051899. 


\section{Thrombolysis}

About $87 \%$ of all the cases of stroke are ischemic and thromboembolic occlusion is the major cause. ${ }^{9}$ The proven interventions for acute ischemic stroke are stroke unit, thrombolysis, aspirin and decompressive surgery for ischemic stroke; and thrombolysis is among the potential treatments used for the management of acute ischemic stroke. ${ }^{10-12}$

Alteplase or rt-PA is the only medically approved biological thrombolysing agent for the treatment of acute ischemic stroke. It is also recommended by most national and international stroke associations as a first-line therapy. ${ }^{9,13}$ Initially Streptokinase was used in routine clinical use but due to safety concerns and lack of evidence of efficacy it has been excluded for use, but there are other agents such as Desmoteplase, Tenecteplase (TNK-TPA), Reteplase and Lanoteplase; some of which have been approved for the thrombolytic treatment of acute myocardial infarction and have given hope for possibility of much safer alternatives in acute ischemic stroke. ${ }^{14-17}$

The NINDS study (1995) concluded that initiation of intravenous rt-PA within $3 \mathrm{~h}$ of stroke onset was at least $30 \%$ more likely to have minimal or no disability at 3 months as compared to the placebo. ${ }^{13}$ The intravenous use of Alteplase within $3 \mathrm{~h}$ of stroke onset was licensed by the Food and Drug Administration (FDA) in North America in 1996 based on NINDS study. ${ }^{14,18}$ After the publication of two trials of intravenous rtPA administered up to $6 \mathrm{~h}$ after ischemic stroke, Alteplase was licensed in European Union in 2002 for the use within $3 \mathrm{~h}$ of ischemic stroke by setting up SITS-MOST (MOnitoring STudy) to assess alteplase within $3 \mathrm{~h}$ of ischemic stroke onset and also initiating a European-Australasian Acute Stroke Study (ECASS) III randomised trial of alteplase use beyond $3 \mathrm{~h} .{ }^{14,19}$ An observational study from SITS-ISTR (International Stroke Thrombolysis Registry) reported Alteplase to be safe at 3-4.5h after ischaemic stroke. ${ }^{19}$ At the moment intravenous Alteplase has been approved for treatment of acute ischemic stroke in Europe for similar patients within $4.5 \mathrm{~h} .{ }^{18}$ In all of these study the intravenous dose was $0.9 \mathrm{mg} / \mathrm{kg}(10 \%$ bolus during one minute and $90 \%$ infusion over $1 \mathrm{~h}$ ) and patients were between 18 to 80 years of age. However, Japan Alteplase Clinical Trial (J-ACT) study suggests a dose of $0.6 \mathrm{mg} / \mathrm{kg}$ for clinical efficacy and safety of Japanese patients. ${ }^{20}$ Recently, the third International Stroke Trial (IST-3) had studied the effect of thrombolysis with $0.9 \mathrm{mg} / \mathrm{kg}$ dose of rt-PA within $6 \mathrm{~h}$ of acute ischaemic stroke including wider age range of patients ( $\sim 53 \%$ of patients above 80 years) further studying the effect on long-term outcomes. ${ }^{21,22}$ The IST-3 with its follow-up study showed thrombolysis within $6 \mathrm{~h}$ improved the functional outcome with no lesser benefit in elderly, though within 7days haemorrhagic episode and death was higher in rt-PA treated group as compared to control despite the fact that at 6 months similar number of patients had died in both the groups. However, the SITS-ISTR for 700 clinical centres practising thrombolysis in 35 countries demonstrated the rate of symptomatic intracerebral haemorrhage of $1.6 \%$ at $3 \mathrm{~h}$ and $2.2 \%$ within $3-4.5 \mathrm{~h}$; mortality rate of $12.2 \%$ at $3 \mathrm{~h}$ and $12.7 \%$ within $3-4.5 \mathrm{~h}$ and functional independence of $56.3 \%$ at $3 \mathrm{~h}$ and $58.0 \%$ within $3-4.5 \mathrm{~h} .{ }^{7,9}$

The initiation of rt-PA requires clinical diagnosis of stroke with no evidence of haemorrhage using CT before $3-4.5 \mathrm{~h}$. Patients of age $\geq 18$ years are only included. Intravenous rt-PA is contraindicated in minor or rapidly resolving stroke symptoms, in those with stroke or serious head trauma within past 3 months, major surgery within 24 days, known history of intracranial haemorrhage, blood pressure more than $185 / 110 \mathrm{mmHg}$, symptoms suggesting subarachnoid haemorrhage, history of gastrointestinal or urinary tract haemorrhage within 21 days, arterial puncture at non-compressible site within 7 days, received heparin within last $48 \mathrm{~h}$, has an elevated prothrombin time and platelet count $<100,000 \mu \mathrm{l}$. Similarly, the relative contraindication of intravenous rt-PA is when there has been seizure at the onset of stroke, serum glucose $<50 \mathrm{mg} / \mathrm{dl}$ or $400 \mathrm{mg} / \mathrm{dl}$, haemorrhagic eye disorder, myocardial infarction in the prior 6 weeks, suspected septic embolism, infective endocarditis and International Normalised Ratio $>1.7 .{ }^{12,14}$

There are several hospital based stroke studies done in Nepal, and the majority of them have studied risk factors and most of them are descriptive. ${ }^{23}$ Hence, Nepal needs to evidently introduce intravenous rt-PA in its clinical setting for treatment of acute ischemic stroke which has been approved for more than a decade ago in developed countries though there are difficulties in implementing in its setting.

\section{Reasons for underuse of rt-PA in ischaemic stroke}

A survey on US population found three potential reasons namely lower patient education, perception of risk on physicians and inadequate reimbursement for low rates of rt-PA use in acute stroke. ${ }^{24}$ Standard use of rt-PA relies on administration in short duration of time of stroke onset and due to less knowledge or unawareness among people about the sign and symptoms of stroke they get admitted in the hospital with delay has been mentioned. There has been a perception of risk in physicians particularly emergency doctors related to the use of rt-PA. A study done by Bobrow et al (2009) in the USA (Arizona and Missouri) to evaluate 
the attitudes and knowledge of emergency physicians (particularly in primary stroke centres with stroke neurology teams) about intravenous rt-PA for acute ischemic stroke showed that there is a need of suitable predicting models for use by emergency physicians and stroke neurologists. ${ }^{25}$ It was known from this survey that most of them who opposed rt-PA were concerned about the risk of haemorrhage and many would agreed to administer rt-PA to acute ischemic stroke patients after a formal consultation with a stroke neurologist by telemedicine. Neurology and radiology is equally important in settings of all countries but the drug cost might be a matter of concern in countries like Nepal.

\section{Factors affecting ischemic stroke}

Stroke occurs predominantly in middle and late years of life. The modifiable risk factors affecting ischemic stroke includes cardiac diseases (mainly atrial fibrillation), diabetes, hypertension, hyperlipidemia, smoking, alcohol consumption and oral contraceptives use. The risk of stroke also depends upon some nonmodifiable factors such as age, gender, race, ethnicity and heredity. The major factors have been discussed in detail. Knowledge about these risk factors led to interventions and preventive measures that reduced the incidence of stroke during the last two decades. ${ }^{26}$ However, many risk factors are yet to be recognized since stroke etiology is not identified in a large proportion of ischemic stroke patients. These risk factors also affect the outcomes of treatment in ischaemic stroke and are vital in predicting the outcomes of stroke after intravenous thrombolysis.

\section{Age}

Most of the thrombolysis treatment has been conducted in patients with acute ischaemic stroke between the age group of $18-80$ years while the treatment for those over age of 80 years has been controversial. ${ }^{27}$ A multivariable analysis of data from the SITS-MOST (2008) has concluded older age as a predictor of poor outcome. ${ }^{19}$ The Copenhagen Stroke study in 1994 has reported that the activities of daily living aspects (stroke outcome) is selectively affected by age. ${ }^{28}$ Analysis of this study in 1999 further mentions that $50 \%$ reduction in the relative risk of poor outcome has been seen with 10 years decrease in age. ${ }^{29}$ In contrast, the IST-3 study (2012) on rt-PA suggests greater benefit in those older than 80 years of age $(P=0.027) .{ }^{21}$

\section{Atrial fibrillation}

Evaluation of the raw data from NINDS trial reported that rt-PA does not improve neurological outcome in patients with atrial fibrillation (AF). ${ }^{30}$ The Japan Multicenter Stroke Investigators' Collaboration (J-MUSIC) study suggest that AF is a predictor of severe stroke and early death in patients with acute ischemic stroke. ${ }^{31,32}$ The findings were explained to be independently associated with lack of recanalization after administration of rt$\mathrm{PA}$ and prevalence of rt-PA resistant larger or older thrombi in AF patients. However, the J-MUSIC study was conducted in small population size, heart disease was not routinely evaluated as well as dose of rt-PA in Japan $(0.6 \mathrm{mg} / \mathrm{kg})$ being lower than the internationally approved dose $(0.9 \mathrm{mg} / \mathrm{kg})$, which all contradicts the significance of the study result.

\section{Blood glucose and diabetes}

ECASS-II trial reports that acute ischemic stroke treated with rt-PA results in poor outcome associated with occurrence of hyperglycemia (HG). ${ }^{33}$ A study done in Neurovascular Hospital of Barcelona (2005) suggests that acute (not chronic) HG can lead to interruption in reperfusion of ischemic pneumbra by interfering fibrinolytic process in rt-PA treated patients and therefore, early recanalization can be achieved by controlling HG. ${ }^{34}$ A significant difference in recanalization rate between patients with low and high admission glucose level ( $p=0.039$ ) was observed without any significance in Glycosylated haemoglobin $(\mathrm{HbA} 1 \mathrm{c})(\mathrm{p}=0.896)$ and fructosamine $(p=0.957)$. It has also been reported that there is a significant association of admission glucose level $>158 \mathrm{mg} / \mathrm{dL}$ with lower recanalization rate and higher National Institute of Health Stroke Scale (NIHSS) score. It has been known that HG decreases fibrinolytic activity through glycation of Annexin II. A retrospective study in a large urban US health system (2006) on the effect of blood glucose (BG) control on mortality after acute stroke concluded that normalization of $B G<130$ $\mathrm{mg} / \mathrm{dL}$ during the first $48 \mathrm{~h}$ significantly $(\mathrm{p}<0.001)$ reduces mortality by 4.6 times compared to persistent $\mathrm{HG}$ and mentions glycemic control as an independent predictor of survival $(p=0.026)$ even after controlling confounders. ${ }^{35}$ However, the UK Glucose Insulin Stroke Trial (GIST-UK) (2007) found that despite significant reduction in plasma blood glucose as well as systolic blood pressure in insulin treated group, the treatment did not show any significant clinical benefits (reduction in mortality or other secondary outcomes) as compared with the control group. ${ }^{36}$ Also a prospective cohort study on non-diabetic stroke patients reports that the stroke mortality rate increases by increased post stroke glucose challenge. ${ }^{37}$

It has been known that diabetes increases the risk of stroke two to three times as compared to nondiabetic patients. ${ }^{38} \mathrm{~A}$ study determining the prevalence of disturbances in glucose metabolism in patients with acute stroke done (2006) found that diabetes being associated with poor outcomes of acute stroke 
$(p<0.001)$ as well as stroke severity along with urinary tract infection and female were independently related to newly recognized diabetes. ${ }^{38}$

\section{Blood pressure and antihypertensive therapy}

A retrospectively study done to determine the association of blood pressure and antihypertensive therapy with clinical outcomes in stroke patients undergoing intravenous thrombolysis from SITS-ISTR (2009) suggested a strong association of high systolic blood pressure after thrombolysis with poor outcome. ${ }^{39}$ In this study patients with moderate hypertension undergoing antihypertensive therapy had favourable outcomes than those with a history of hypertension with no antihypertensive therapy who had higher symptomatic haemorrhage. The results contradicts with the earlier studies suggesting less favourable outcome after antihypertensive therapy. ${ }^{40,41}$ However, these studies were conducted on small number of patients and different outcome measures were used.

\section{Hyperlipidemia}

A study on the impact of serum cholesterol level on the outcome following ischaemic stroke (2000) showed that patients with high cholesterol level had more than twice lower risk of death and poor functional outcome at one month than those with normal cholesterol. ${ }^{42}$ In contrast the Stroke Prevention by Aggressive Reduction in Cholesterol Levels (SPARCL) trial suggests treatment of hyperlipidemia with atorvastatin in patients with acute ischaemic stroke but without the history of coronary heart disease reduced the overall incidence of stroke with small incidence of haemorrhagic stroke. ${ }^{43}$ However, the Multiple Risk Factor Intervention Trial showed the risk of death due to non-haemorrhagic stroke increases with the increase in level of serum cholesterol whereas there was inverse relationship between the risk of death due to haemorrhagic stroke and serum cholesterol level. ${ }^{44,45}$ There has been controversies about the increased serum cholesterol and its risk on stroke treatment. A meta-analysis showed no association between total cholesterol levels and stroke whereas another meta analysis showed relative stroke risk with cholesterol level above $200 \mathrm{mg} / \mathrm{dL} .{ }^{45}$ Interestingly severe white matter hyperintensity (WMH) was found in acute ischaemic stroke with hyperlipidemia and thus hyperlipidemia may have a protective role in cerebral small-vessel disease as $\mathrm{WMH}$ is supposed to expose diseased small cerebral vasculature. ${ }^{46}$

\section{Smoking}

A meta-analysis for determining the relation between cigarette smoking and stroke on 32 separate studies concluded that cigarette smoking is strongly related to risk of stroke. ${ }^{47}$ The overall relative risk was found to be $1.5(95 \% \mathrm{Cl}$ of 1.4 to 1.6$)$. Furthermore, the relative risk increased with increase in dose of smoking. Ex-smokers had twice more risk of stroke before 75 years. Interestingly, studies have shown less incidence of haemorrhage in current smokers. ${ }^{19,48}$ Another study also concluded recent smokers receiving thrombolysis had lesser median stroke severity and low mortality over one year. ${ }^{49}$

\section{Gender}

A systematic review on effect of gender on thrombolysis in acute stroke reported inconsistency in literatures and suggests for consideration of gender in treatment of ischemic stroke. ${ }^{50}$ Stroke outcome studies on IV rtPA have shown more neurological improvement ${ }^{51}$ and arterial recanalization rate $^{52}$ in women. Evaluation of gender differences in the efficacy and safety outcomes of IV rt-PA using clinical registry and systematic review suggests no gender differences in outcome at 3 months among patients treated with IV t-PA. ${ }^{53}$ This is also supported by The Serbian Experience with Thrombolysis in Ischemic Stroke (SETIS) study ${ }^{54}$ and Canadian Alteplase For Stroke Effectiveness Study (CASES). ${ }^{55}$

However, pooled analysis of randomised controlled trials [NINDS, Alteplase Thrombolysis for Acute Noninterventional Therapy in Ischemic Stroke (ATLANTIS) A and B, ECASS-II] on intravenous rt-PA in acute ischaemic stroke have shown significantly $(p=0.03)$ less probability of excellent outcome after 90 days in untreated women as compared to untreated men. ${ }^{56}$ The SETIS study and CASES has also mentioned that women might benefit more from intravenous thrombolysis in acute ischaemic stroke as they have more chance of excellent outcome than men providing supporting evidence that studies have shown presence of higher activity of Plasminogen Activator Inhibitor-1 or PAl-1 (an independent predictor of thrombolysis resistance) in women than in men.

\section{CONCLUSIONS}

The prevalence and incidence of stroke is increasing day-by-day worldwide. Ischemic stroke is responsible for most of the death caused by stroke. Many factors influence the outcome of the stroke recovery as well as the treatment. Thrombolysis using rt-PA is one of the promising therapies for acute ischemic stroke. Most national and international stroke associations have recommended Alteplase as a first-line therapy for acute ischemic stroke. It has been approved in Europe within $4.5 \mathrm{hrs}$ in patients between $18-80$ years 
but its underuse is a matter of concern. The risk of haemorrhage has been a major hindrance in the use of rt-PA. There is a vital need for a reliable, easy and less time-consuming tool that can reduce this perception of risk as well as increase the efficacy of the treatment protocol by Alteplase. Multivariable analysis of outcome predictors would allow identification of patients suitable for thrombolysis. Nepal needs to evidently start intravenous thrombolysis with the criteria provided by NINDS and SITS study. This review mainly focuses on articles after 2002 as Alteplase was licensed in Europe in 2002. The literature search was also limited to full text published articles in English.

\section{REFERENCES}

1. Di Carlo A. Human and economic burden of stroke. Age Ageing. 2009;38(1):4-5.

2. Rosamond W, Flegal K, Furie K, Go A, Greenlund K, Haase $\mathrm{N}$, et al. Heart disease and stroke statistics-2008 update: a report from the American Heart Association Statistics Committee and Stroke Statistics Subcommittee. Circulation. 2008;117(4):e25-146.

3. European cardiovascular disease statistics 2008. European Heart Network. Brussels; 2008.

4. Saka O, McGuire A, Wolfe C. Cost of stroke in the United Kingdom. Age Ageing. 2009;38(1):27-32.

5. Kulshreshtha A, Anderson LM, Goyal A, Keenam NL. Stroke in South Asia: A Systematic Review of Epidemiologic Literature from 1980 to 2010. Neuroepidemiology. 2012;38(9):123-9.

6. Lees KR, Bluhmki E, von Kummer R, Brott TG, Toni D, Grotta JC, et al. Time to treatment with intravenous alteplase and outcome in stroke: an updated pooled analysis of ECASS, ATLANTIS, NINDS, and EPITHET trials. Lancet. 2010;375(9727):1695-703.

7. Counsell C, Dennis M, McDowall M, Warlow C. Predicting outcome after acute and subacute stroke: development and validation of new prognostic models. Stroke. 2002; 33(4):1041-7.

8. Reid JM, Gubitz GJ, Dai D, Kydd D, Eskes G, Reidy $\mathrm{Y}$, et al. Predicting functional outcome after stroke by modelling baseline clinical and CT variables. Age Ageing. 2010;39(3):360-6.

9. Donnan GA, Fisher M, Macleod M, Davis SM. Stroke. Lancet. 2008;371(9624):1612-23.

10. Intercollegiate Stroke Working Party (ISWP). National clinical guidelines for stroke. 2nd ed. Suffolk: The Lavenham Press Ltd;2010.

11. Jivan K, Ranchod K, Modi G. Management of ischemic stroke in the acute setting: review of the current status. Cardiovasc J Afr. 2013;24(3):86-92.

12. Rana PV. Early management of acute ischemic stroke: review of literature and proposed guidelines. Kathmandu Univ Med J. 2004;2(1):55-66.

13. Wahlgren N, Ahmed N, Davalos A, Ford GA, Grond M, Hacke W, et al. Thrombolysis with alteplase for acute ischaemic stroke in the Safe Implementation of Thrombolysis in Stroke-Monitoring Study (SITS-MOST): an observational study. Lancet. 2007;369(9558):275-82.

14. Blakeley JO, Llinas RH. Thrombolytic therapy for acute ischemic stroke. J Neurol Sci. 2007;261(1-2),55-62.
15. Nordt TK, Bode C. Thrombolysis: newer thrombolytic agents and their role in clinical medicine. Heart. 2003;89(11):1358-62.

16. Scottish Intercollegiate Guidelines Network. Management of patients with stroke or TIA: assessment, investigation, immediate management and secondary prevention, a national clinical guideline. Number 108, SIGN: Edinburgh. 2008

17. Hacke W, Albers G, Al-Rawi Y, Bogousslavsky J, Davalos A, Eliasziw M, et al. The Desmoteplase in Acute Ischemic Stroke Trial (DIAS): a phase II MRI-based 9-hour window acute stroke thrombolysis trial with intravenous desmoteplase. Stroke. 2005; 36(1):66-73.

18. Wardlaw JM, Murray V, Berge E, del Zoppo G, Sandercock P, Lindley RL, Cohen G. Recombinant tissue plasminogen activator for acute ischaemic stroke: an updated systematic review and meta-analysis. Lancet. 2012; 379(9834):2364-72

19. Wahlgren N, Ahmed N, Eriksson N, Aichner F, Bluhmki E, Davalos A, et al. Multivariable analysis of outcome predictors and adjustment of main outcome results to baseline data profile in randomized controlled trials: Safe Implementation of Thrombolysis in Stroke-MOnitoring STudy (SITS-MOST). Stroke. 2008;39(12):3316-22.

20. Yamaguchi T, Mori E, Minematsu K, Nakagawara J, Hashi $\mathrm{K}$, Saito I, et al. Alteplase at $0.6 \mathrm{mg} / \mathrm{kg}$ for acute ischemic stroke within 3 hours of onset: Japan Alteplase Clinical Trial (J-ACT). Stroke. 2006;37(7):1810-15.

21. IST-3 collaborative group, Sandercock P, Wardlaw JM, Lindley RI, Dennis M, Cohen G, et al. The benefits and harms of intravenous thrombolysis with recombinant tissue plasminogen activator within $6 \mathrm{~h}$ of acute ischaemic stroke (the third international stroke trial [IST-3]): a randomised controlled trial. Lancet. 2012;379(9834):2352-63

22. IST-3 collaborative group. Effect of thrombolysis with alteplase within $6 \mathrm{~h}$ of acute ischaemic stroke on long-term outcomes (the third International Stroke Trial [IST-3]): 18-month follow-up of a randomised controlled trial. Lancet Neurol. 2013;12(8):768-76

23. Shaik MM, Loo KW, Gan SH. Burden of stroke in Nepal. Int J Stroke. 2012:7(6):517-20

24. Bambauer KZ, Johnston SC, Bambauer DE, Zivin JA. Reasons why few patients with acute stroke receive tissue plasminogen activator. Arch Neurol. 2006;63(5):661-4.

25. Bobrow BJ, Demaerschalk BM, Wood JP, Villarin A, Clark L, Jennings A. Views of emergency physicians on thrombolysis for acute ischemic stroke. J Brain Dis. 2009;1: 29-37.

26. Coull A, Lovett JK, Rothwell PM; Oxford Vascular Study. Population based study of early risk of stroke after 
transient ischaemic attack or minor stroke: implications for public education and organisation of services. BMJ. 2004;328(7435):326-8.

27. Ford GA, Sandercock P. Current controversies: thrombolysis for patients with acute ischaemic stroke aged over 80 . J R Coll Physicians Edinb. 2010;40(1):49-53.

28. Nakayama H, Jorgensen HS, Raaschou HO, Olsen TS. The influence of age of stroke outcome: the Copenhagen Stroke Study. Stroke. 1994;25(4):808-13.

29. Jørgensen HS, Reith J, Nakayama H, Kammersgaard LP, Raaschou HO, Olsen TS. What determines good recovery in patients with the most severe strokes? The Copenhagen Stroke Study. Stroke. 1999;30(10):2008-12.

30. Brown DL, Johnston KC, Wagner DP, Haley EC Jr. Predicting major neurological improvement with intravenous recombinant tissue plasminogen activator treatment of stroke. Stroke. 2004; 35(1):147-50.

31. Kimura K, Kazui S, Minematsu K, Yamaguchi T; Japan Multicentre Stroke Investigator's Collaboration. Analysis of 16,922 patients with acute ischemic stroke and transient ischemic attack in Japan. A hospital-based prospective registration study. Cerebrovasc Dis. 2004;18(1):47-56.

32. Kimura K, Iguchi Y, Shibazaki K, Iwanaga T, Yamashita S, Aoki J. IV t-PA therapy in acute stroke patients with atrial fibrillation. J Neurol Sci. 2009;276(1-2):6-8.

33. Yong M, Kaste M. Dynamic of hyperglycemia as a predictor of stroke outcome in the ECASS-II trial. Stroke. 2008;39(10):2749-55.

34. Ribo M, Molina C, Montaner J, Rubiera M, Delgado-Mederos $\mathrm{R}$, Arenillas JF, et al. Acute hyperglycemia state is associated with lower tPA-induced recanalization rates in stroke patients. Stroke. 2005;36(8):1705-9.

35. Gentile NT, Seftchick MW, Huynh T, Kruus LK, Gaughan J. Decreased mortality by normalizing blood glucose after acute ischemic stroke. Acad Emerg Med. 2006;13(2): 174-80.

36. Gray CS, Hildreth AJ, Sandercock PA, OConnell JE, Johnston DE, Cartidge NE, et al. Glucose-potassium-insulin infusions in the management of post-stroke hyperglycaemia: the UK Glucose Insulin in Stroke Trial (GIST-UK). Lancet Neurol. 2007;6(5):397-406.

37. Batty GD, Kivimaki M, Davey Smith G, Marmot MG, Shipley MJ. Post-challenge blood glucose concentration and stroke mortality rates in non-diabetic men in London: 38-year follow-up of the original Whitehall prospective cohort study. Diabetologia. 2008; 51(7):1123-6.

38. Matz K, Keresztes K, Tatschl C, Nowotny M, Dachenhausen A, Brainin M, Tuomilehto J. Disorders of glucose metabolism in acute stroke patients: an underrecognized problem. Diabetes Care. 2006;29(4):792-7.

39. Ahmed N, Wahlgren N, Brainin M, Castillo J, Ford GA, Kaste $\mathrm{M}$, et al. Relationship of blood pressure, antihypertensive therapy, and outcome in ischaemic stroke treated with intravenous thrombolysis: retrospective analysis from Safe Implementation of Thrombolysis in Stroke-International Stroke Thrombolysis Register (SITS-ISTR). Stroke. 2009;40(7):2442-9.

40. Brott T, Lu M, Kothari R, Fagan SC, Frankel M, Grotta JC, et al. Hypertension and its treatment in the NINDS rt-PA Stroke Trial. Stroke. 1998;29(8):1504-9.
41. Lindsberg PJ, Soinne L, Roine RO, Salonen O, Tatlisumak T, Kallela M, et al. Community-based thrombolytic therapy of acute ischemic stroke in Helsinki. Stroke. 2003;34(6):1443-9.

42. Vauthey C, de Freitas GR, van Melle G, Devuyst G, Bogousslavsky J. Better outcome after stroke with higher serum cholesterol levels. Neurology. 2000;54(10):1944-9.

43. Amarenco P, Bogousslavsky J, Callahan A 3rd, Goldstein LB, Hennerici M, Rudolph AE, et al. High-dose atorvastatin after stroke or transient ischemic attack. N Engl J Med. 2006;355(6):549-59.

44. Iso H, Jacobs DR Jr, Wentworth D, Neaton JD, Cohen JD. Serum cholesterol levels and six-year mortality from stroke in 350,977 men screened for the Multiple Risk Factor Intervention Trial. N Engl J Med. 1989;320(14):904-10.

45. Paciaroni M, Hennerici M, Agnelli G, Bogousslavsky J. Stations and stroke prevention. Cerebrovasc Dis. 2007;24(2-3):170-82.

46. Jimenez-Conde J, Biffi A, Rahman R, Kanakis A, Butler C, Sonni $S$, et al. Hyperlipidemia and reduced white matter hyperintensity volume in patients with ischemic stroke. Stroke. 2010;41(3):437-42.

47. Shinton R, Beevers G. Meta-analysis of relation between cigarette smoking and stroke. BMJ. 1989;298(6676):789-94.

48. The NINDS t-PA Stroke Study Group. Intracerebral hemorrhage after intravenous t-PA therapy for ischemic stroke. Stroke. 1997;28(11):2109-18.

49. Ovbiagele B, Saver JL. The smoking-thrombolysis paradox and acute ischemic stroke. Neurology. 2005;65(2):293-5.

50. De Silva DA, Ebinger M, Davis SM. Gender issues in acute stroke thrombolysis. J Clin Neurosci. 2009;16(4):501-4.

51. Di Legge S, Saposnik G, Nilanont Y, Hachinski V. Neglecting the difference: does right or left matter in stroke outcome after thrombolysis? Stroke. 2006;37(8):2066-9.

52. Savitz SI, Schlaug G, Caplan L, Selim M. Arterial occlusive lesions recanalize more frequently in women than in men after intravenous tissue plasminogen activator administration for acute stroke. Stroke. 2005;36(7):1447-51.

53. Meseguer E, Mazighi M, Labreuche J, Arnaiz C, Cabrejo $\mathrm{L}$, Slaoui $\mathrm{T}$, et al. Outcome of intravenous recombinant tissue plasminogen activator therapy according to gender: a clinical registry study and systematic review. Stroke. 2009;40(6):2104-10.

54. Jovanovic DR, Beslac-Bumbasirevic Lj, Budimkic M, Pekmezovic T, Zivkovic M, Kostic VS;SETIS Investigation Group. Do women benefit more from systemic thrombolysis in acute ischemic stroke? A Serbian experience with thrombolysis in ischemic stroke (SETIS) study. Clinl Neurol Neurosurg. 2009;111(9):729-32.

55. Kent DM, Buchan AM, Hill MD. The gender effect in stroke thrombolysis. Of CASES, controls and treatment-effect modification. Neurology. 2008;71(14):1080-3.

56. Kent DM, Price LL, Ringleb P, Hill MD, Selker HP. Sex-based differences in response to recombinant tissue plasminogen activator in acute ischemic stroke: a pooled analysis of randomized clinical trials. Stroke. 2005;36(1):62-5. 